\title{
TREATMENT PROFILES AND RISK FACTORS FOR CLINICAL OUTCOMES OF CONFIRMED COVID-19 AND PNEUMONIA PATIENTS AT FATMAWATI GENERAL HOSPITAL JAKARTA
}

\author{
NOFRIA RIZKI AMALIA HARAHAP ${ }^{1 *}$, RETNOSARI ANDRAJATI ${ }^{1}$, AHMAD SUBHAN ${ }^{2}$ \\ ${ }^{1}$ Department of Clinical Pharmacy, Faculty of Pharmacy, University of Indonesia, Depok, Indonesia. ${ }^{2}$ Department of Pharmacy, Fatmawati \\ General Hospital, Jakarta, Indonesia. Email: nofria.rizki@gmail.com
}

Received: 28 July 2021, Revised and Accepted: 2 September 2021

\section{ABSTRACT}

Objectives: This study aimed to investigate the treatment profiles and the risk factor for clinical outcomes of confirmed coronavirus disease-19 (COVID-19) and pneumonia patients at Fatmawati General Hospital Jakarta.

Methods: This research was conducted using a cross-sectional design at Fatmawati General Hospital Jakarta. A total of 72 adults COVID-19 confirmed patients with pneumonia diagnosis from March to December 2020 were included in our study. Data were collected retrospectively by the patients' medical record.

Results: The percentage of critical or severe confirmed COVID-19 with pneumonia inpatients (66.7\%) was higher than those who were having non-severe diseases (33.3\%). 36 (50\%) death were reported in our patient population. Patients received antiviral, antibiotics, and steroids during a treatment period. The most common antibiotic regimens were levofloxacin intravenous (IV) (18.8\%) and azithromycin per oral (P0) (13.9\%). Oseltamivir (83.3\%) was the most frequently prescribed antiviral for the patients. A total of $41.7 \%$ of patients used steroids. In multivariable logistic regression analyses, the severity of COVID-19 disease was the only predictive factor of death in COVID-19 and pneumonia patients (p<0.001, OR=26.714, 95\% confidence intervals: 5.526-129.135).

Conclusion: Some drugs (antiviral, antibiotics, and steroids) have been prescribed to the confirmed COVID-19 with pneumonia patients. Oseltamivir and levofloxacin were the widely used antiviral and antibiotic agents in this study. The analysis showed that the disease severity was statistically associated with patient's clinical outcomes. COVID-19 patients with the severe illness have a greater risk of death.

Keywords: Clinical outcome, Coronavirus disease-19, Pneumonia, Risk factors.

(C) 2021 The Authors. Published by Innovare Academic Sciences Pvt Ltd. This is an open access article under the CC BY license (http://creativecommons.org/ licenses/by/4.0/) DOI: http://dx.doi.org/10.22159/ajpcr.2021v14i9.42891. Journal homepage: https://innovareacademics.in/journals/index.php/ajpcr

\section{INTRODUCTION}

Coronavirus disease-19 (COVID-19) pandemic has drastically affected global health. From December 2019 to August 6, 2021, the disease caused 4,265,903 (2.12\%) deaths from 200,840,180 confirmed COVID-19 patients worldwide [1], while the number of COVID-19 cases in Indonesia reached 3,666,031 confirmed cases and 107,096 death cases till August 8, 2021 [2]. COVID-19 is an infectious disease by a new type of coronavirus, severe acute respiratory syndrome coronavirus-2 (SARS-CoV-2) [3]. It was more dangerous if pneumonia attacks COVID-19 patients as a complication. The mortality rate of COVID-19 patients with pneumonia was 7.3$8.2 \%$ [4]. The rapidly increasing of patients brought a big challenge to public health. Nowadays, definitive therapy for COVID-19 has not been found yet. However, some drugs that have been used for other indications, or new drugs that are still in trials are being researched in various parts of the world. Based on the new WHO COVID-19 guideline (2021), empiric therapy with an antiviral should be considered for patients with severe disease or at risk for severe influenza. Antibiotics also have been used to prevent and treat bacterial coinfection in COVID-19 [5,6]. Profile treatment and the association between demographic or clinical risk factors on the clinical outcomes of COVID-19 and pneumonia patients in Indonesia have been described in only a few studies. Rozaliyani et al. found that mortality was correlated with older age, male, and comorbidity (pre-existing hypertension) [7]. Thus, the purpose of this study was to investigate the treatment profiles and the risk factor for clinical outcomes of confirmed COVID-19 patients and pneumonia at Fatmawati Hospital Jakarta.

\section{METHODS}

Study site

The study was conducted in Fatmawati General Hospital Jakarta, Indonesia, from October 2020 through June 2021. The hospital is one of the referral hospitals for COVID-19 patients in Indonesia with a total of 1165 COVID-19 inpatients from March to December 2020.

\section{Study population description}

The study was carried out among COVID-19 confirmed patients with pneumonia diagnosis from March to December 2020 at Fatmawati General Hospital Jakarta.

\section{Study design}

The study design was cross-sectional to collect information about the demographic and clinical characteristics, treatments, and the risk factor of COVID-19 with pneumonia patients.

\section{Inclusion criteria}

Inclusion criteria included confirmed COVID-19 patients diagnosed with pneumonia by the doctor based on clinical examination and chest X-ray results and adult patients (aged $\geq 18$ years).

\section{Exclusion criteria}

Exclusion criteria were patients with incomplete medical record data, pregnant, and breastfeeding women.

\section{Data collection}

Data were collected by patient's medical records. 
Data analysis

Data analysis was performed using Statistical Product and Service Solutions (SPSS) program version 23. Descriptive analysis for patient characteristics and the treatment profiles was presented in frequency or percentage. The analysis of the correlation between age, gender, comorbidities, COVID-19 severity, and clinical outcomes was carried out by the Chi-square test and assuming that there is a significant difference if $\mathrm{p}<0.05$. Logistic regression was performed to determine the risk factors for patient's clinical outcomes. Crude, adjusted odds ratios (OR), and 95\% confidence intervals (CI) are provided as estimates of risk for each outcome.

\section{Ethical issues}

The Ethics Committee of the Fatmawati Central General Hospital has approved this study with the number: 23/KEP/XII/2020.

\section{RESULTS}

The results showed that of 118 patients diagnosed with confirmed COVID-19 and pneumonia from March to December 2020, 72 patients met the inclusion criteria, and 46 patients were excluded ( 44 patients medical records were inaccessible, and two pediatric patients).

\section{Demographic and clinical characteristics of patients}

The demographic features of the respondents included age, gender, length of stay, COVID-19 severity, comorbidities, clinical outcomes, and symptoms (Table 1 ). The mean age of all patients was $53.13 \pm 12.61$ years. 42 (58.3\%) were males while $30(41.7 \%)$ were females. The percentage of critical or severe confirmed COVID-19 with pneumonia inpatients $(66.7 \%)$ was higher than those who were having non-severe diseases (33.3\%). Comorbidities of patients were hypertension (44.4\%), diabetes mellitus (41.7\%), renal disease (30.6\%), and cardiovascular disease (16.7\%). $36(50 \%)$ death were reported in our patient population. The most common symptoms of patients were dyspnea (95.8\%), cough (87.5\%), and fever (68.1\%) (Table 1).

\section{Table 1: Demographic and clinical characteristics of patients}

\begin{tabular}{|c|c|c|}
\hline Characteristics & Frequency (n) & Percentage (\%) \\
\hline Age group (Mean \pm SD) & $53.13 \pm 12.61$ & \\
\hline 1. $18-65$ years & 61 & 84.7 \\
\hline 2. $>65$ years & 11 & 15.3 \\
\hline Length of stay /LoS (Median/IQR) & $15.50 / 9-20.75$ & \\
\hline \multicolumn{3}{|c|}{ Gender } \\
\hline 1. Female & 30 & 41.7 \\
\hline 2. Male & 42 & 58.3 \\
\hline \multicolumn{3}{|l|}{ COVID-19 severity } \\
\hline 1. Non severe & 24 & 33.3 \\
\hline 2. Severe or critical & 48 & 66.7 \\
\hline \multicolumn{3}{|l|}{ Comorbidity } \\
\hline 1. No & 22 & 30.6 \\
\hline 2. Yes & 50 & 69.4 \\
\hline \multicolumn{3}{|l|}{ Comorbid diseases } \\
\hline 1. Hypertension & 32 & 44.4 \\
\hline 2. Diabetes mellitus & 30 & 41.7 \\
\hline 3. Cardiovascular disease & 12 & 16.7 \\
\hline 4. Renal disease & 22 & 30.6 \\
\hline \multicolumn{3}{|l|}{ Clinical outcomes } \\
\hline 1. Healed & 36 & 50 \\
\hline 2. Death & 36 & 50 \\
\hline \multicolumn{3}{|l|}{ Symptoms } \\
\hline 1. Dyspnea & 69 & 95.8 \\
\hline 2. Fever & 49 & 68.1 \\
\hline 3. Cough & 63 & 87.5 \\
\hline 4. Nasal congestion & 12 & 16.7 \\
\hline 5. Malaise & 28 & 38.9 \\
\hline 6. Headache & 10 & 13.9 \\
\hline 7. Nausea or vomiting & 24 & 33.3 \\
\hline 8. Sore throat & 8 & 11.1 \\
\hline 9. Anosmia or ageusia & 2 & 2.8 \\
\hline
\end{tabular}

Based on Table 2, it can be seen that thirty (41.7\%) patients received steroid, and $70(97.2 \%)$ antiviral therapy such as remdesivir (1.4\%), favipiravir (9.7\%), oseltamivir (83.3\%), and the combination of lopinavir and ritonavir (2.8\%). During treatment, the total antibiotic use was 144 regimens. The pattern of antibiotic use was 87 (60.4\%) of monotherapy and 57 (39.6\%) of combination antibiotics (Table 2).

It was known that of 31 patients aged 18-65 years, 31 people (50.8\%) got clinical outcomes healed, while from 11 patients aged $>65$ years, 5 people (45.5\%) got clinical outcomes recovered. The total of death in patients aged 18-65 years and >65 years was $30(49.2 \%)$ and $6(54.5 \%)$, respectively. Age did not correlate with the clinical outcome of COVID-19 with pneumonia patients with $\mathrm{p}=1.000>0.05$. The percentage recovered and death in female patients was $18(60 \%)$ and 12 (40\%), while in male patients, was 18 (42.9\%) and 24 (57.1\%). Gender did not associate with the patient's clinical outcome with $\mathrm{p}=0.232>0.05$. Patients with comorbidities had a $40 \%$ clinical result healed and $60 \%$ death. $16(72.7 \%)$ patients without comorbidities healed and $6(27.3 \%)$ died. Sig. value showed a value of $0.021<0.05$, which means that comorbidities correlated with the clinical outcome of COVID19 with pneumonia patients. Meanwhile, COVID patients with severe or critical diseases $(70.8 \%)$ had greater mortality than non-severe COVID-19 patients (8.3\%). COVID-19 severity disease statistically affected the patient's clinical outcomes with $\mathrm{p}<0.001$ (Table 3).

In multivariable logistic regression analyses, older age (aOR 1.361, 95\% CI $0.237-7.807, \mathrm{p}=0.729$ ), male gender (aOR 1.863, 95\% CI $0.568-$ $6.116, p=0.305$ ), and present comorbidities (aOR 2.577, 95\% CI 0.693$9.590, p=0.158$ ) were not associated with patient's clinical outcomes.

Table 2: The treatment profiles in adult confirmed COVID-19 with pneumonia patients

\begin{tabular}{|c|c|c|}
\hline Therapies administered & Total (n) & $\%$ \\
\hline \multicolumn{3}{|l|}{ Antiviral } \\
\hline Remdesivir & 1 & 1.4 \\
\hline Favipiravir & 7 & 9.7 \\
\hline Oseltamivir & 60 & 83.3 \\
\hline Lopinavir+Ritonavir & 2 & 2.8 \\
\hline Not used & 2 & 2.8 \\
\hline \multicolumn{3}{|l|}{ Antibiotic (N: 144) } \\
\hline Levofloxacin (IV) & 27 & 18,8 \\
\hline Azithromycin (PO) & 20 & 13,9 \\
\hline Levofloxacin (PO) & 7 & 4,9 \\
\hline Cefoperazone (IV) & 2 & 1,4 \\
\hline Piperacillin tazobactam (IV) & 3 & 2,1 \\
\hline Ceftriaxone (IV) & 6 & 4,2 \\
\hline Meropenem (IV) & 7 & 4,9 \\
\hline Amikacin (IV) & 5 & 3,5 \\
\hline Tigecycline (IV) & 6 & 4,2 \\
\hline Ceftaroline fosamil (IV) & 2 & 1,4 \\
\hline Ampicillin sulbactam (IV) & 2 & 1,4 \\
\hline Meropenem (IV)+ Amikacin (IV)+Vancomycin (IV) & 2 & 1,4 \\
\hline Meropenem (IV) + Levofloxacin (IV) & 13 & 9,0 \\
\hline Meropenem (IV) + Vancomycin (IV) & 2 & 1.4 \\
\hline Moxifloxacin (IV) + Meropenem (IV) & 2 & 1.4 \\
\hline Levofloxacin (IV) + Piperacillin tazobactam (IV) & 1 & 0.7 \\
\hline Amikacin (IV) + Vancomycin (IV) & 2 & 1.4 \\
\hline Ceftriaxone (IV) + Levofloxacin (IV) & 12 & 8.3 \\
\hline Ceftriaxone (IV) + Azithromycin (PO) & 5 & 3.5 \\
\hline Ampicillin-sulbactam (IV) + Levofloxacin (IV) & 7 & 4.9 \\
\hline Meropenem (IV) + Amikacin (IV) & 5 & 3.5 \\
\hline Levofloxacin (IV) + Meropenem (IV) + & 2 & 1.4 \\
\hline \multicolumn{3}{|l|}{ Vancomycin (IV) } \\
\hline Levofloxacin (IV) + Ceftaroline fosamil (IV) & 2 & 1,4 \\
\hline Azithromycin (PO) + Ampicillin-sulbactam (IV) & 1 & 0,7 \\
\hline Ampicillin-sulbactam (IV) + Moxifloxacin (IV) & 1 & 0,7 \\
\hline \multicolumn{3}{|l|}{ Steroid } \\
\hline Yes & 30 & 41.7 \\
\hline No & 42 & 58.3 \\
\hline
\end{tabular}


Table 3: Bivariate analysis of correlation between age, gender, comorbidities, and COVID-19 severity and clinical outcomes

\begin{tabular}{|c|c|c|c|c|c|}
\hline \multirow[t]{2}{*}{ Characteristics } & \multicolumn{2}{|c|}{ Clinical outcomes (\%) } & \multirow[t]{2}{*}{ p-value } & \multirow[t]{2}{*}{ OR } & \multirow[t]{2}{*}{ CI 95\% } \\
\hline & Healed & Death & & & \\
\hline \multicolumn{6}{|l|}{ Age } \\
\hline 1. $18-65$ years & $31(50.8)$ & $30(49.2)$ & 1.000 & 1.24 & $\begin{array}{l}0.342- \\
4.498\end{array}$ \\
\hline $\begin{array}{l}\text { 2. }>65 \text { years } \\
\text { Gender }\end{array}$ & $5(45.5)$ & $6(54.5)$ & & & \\
\hline 1. Female & $18(60)$ & $12(40)$ & 0.232 & 2.000 & $\begin{array}{l}0.772- \\
5.184\end{array}$ \\
\hline $\begin{array}{l}\text { 2. Male } \\
\text { Comorbidity }\end{array}$ & $18(42.9)$ & $24(57.1)$ & & & \\
\hline 1. No & $16(72.7)$ & $6(27.3)$ & 0.021 & 4.000 & $\begin{array}{l}1.337- \\
11.965\end{array}$ \\
\hline $\begin{array}{l}\text { 2. Yes } \\
\text { COVID-19 } \\
\text { severity }\end{array}$ & $20(40)$ & $30(60)$ & & & \\
\hline 1. Non severe & 22 (91.7) & $2(8.3)$ & $<0.001$ & 26.714 & $\begin{array}{l}5.526- \\
129.135\end{array}$ \\
\hline $\begin{array}{l}\text { 2. Severe/ } \\
\text { critical }\end{array}$ & $14(29.2)$ & $34(70.8)$ & & & \\
\hline
\end{tabular}

However, the COVID-19 severity disease (aOR 26.714, 95\% CI 5.526$129.135, \mathrm{p}<0.001$ ) was predictive of death in confirmed COVID-19 and pneumonia patients (Table 4).

\section{DISCUSSION}

Our study's median length of stay as 15.50 days (IQR 9-20.75) was not much different from the median length of stay of positive COVID-19 patients with CAP and VAP pneumonia, which was 14.5 days (IQR 9.5-28.1) [8]. However, the proportion of deaths in this study was higher $(50 \%)$ than the previous study in positive COVID-19 patients with pneumonia in Russia (18.75\%) [4]. SARS-CoV-2 infection can increase an individual's susceptibility to secondary bacterial infections such as pneumonia. Lung cells infected by SARS-CoV-2 causes damage to the infrastructure of the lung through suppression of the host immune system. Suppression of the immunity by the virus through upregulation of membrane surface proteins expression of the host cell, induction of type I interferon overproduction resulting in dysregulation of cytokines and chemokines, and impaired phagocytic function of alveolar macrophages (AM). This virus-induced lung epithelial damage can cause bacteria to attach, proliferate, and attack lung cells $[5,9]$.

During treatment, antiviral, antibiotics, and steroids were prescribed to patients. According to the COVID-19 protocol by the Indonesian Doctor Association, the recommendations of the antiviral for mild to severe/ critical COVID-19 disease were oseltamivir (Tamiflu), favipiravir (Avigan), or remdesivir [10]. The results showed that oseltamivir was the most common antiviral used in patients. Oseltamivir is indicated for the treatment and prevention of influenza. The mechanism of action of oseltamivir is through neuraminidase inhibition (neuraminidase inhibitor) [11]. Influenza viruses require the enzyme neuraminidase to release newly formed viruses from infected cells at the end of the replication process. Oseltamivir carboxylate as the active metabolite of oseltamivir will interact with neuraminidase. This causes a conformational change in the active site of the enzyme so that enzyme activity is inhibited and the spread of the virus in the respiratory tract decreases [12].

Based on the new WHO COVID-19 management guidelines (2021), empiric antimicrobial therapy is recommended for patients with suspected or confirmed severe COVID-19. The selection of empirical antimicrobial administration should consider the clinical diagnosis, local epidemiology, susceptibility data, and national treatment guidelines [6]. The most common antibiotic regimens were levofloxacin intravenous (IV) (18.8\%) and azithromycin per oral (PO) (13.9\%). Based
Table 4: Risk factors for clinical outcomes among adult COVID-19 confirmed with pneumonia patients

\begin{tabular}{|c|c|c|c|c|c|}
\hline \multirow[t]{2}{*}{ Characteristics } & \multicolumn{2}{|c|}{ Bivariate } & \multicolumn{2}{|c|}{ Multivariate } & \multirow[t]{2}{*}{ CI $95 \%$} \\
\hline & OR & p-value & aOR & p-value & \\
\hline \multicolumn{6}{|l|}{ Age } \\
\hline 1. $18-65$ years & 1.000 & 1.24 & 1.361 & 0.729 & $\begin{array}{l}0.237- \\
7.807\end{array}$ \\
\hline \multicolumn{6}{|l|}{ 2. $>65$ years } \\
\hline \multicolumn{6}{|l|}{ Gender } \\
\hline 1. Female & 0.232 & 2.000 & 1.863 & 0.305 & $\begin{array}{l}0.568- \\
6.116\end{array}$ \\
\hline \multicolumn{6}{|l|}{ 2. Male } \\
\hline \multicolumn{6}{|l|}{ Comorbidity } \\
\hline 1. No & 0.021 & 4.000 & 2.577 & 0.158 & $\begin{array}{l}0.693- \\
9.590\end{array}$ \\
\hline \multicolumn{6}{|l|}{ 2. Yes } \\
\hline \multicolumn{6}{|l|}{ COVID-19 severity } \\
\hline 1. Non severe & $<0.001$ & 26.714 & 26.714 & $<0.001$ & $\begin{array}{l}5.526- \\
129.135\end{array}$ \\
\hline 2. Severe/critical & & & & & \\
\hline
\end{tabular}

on a study by Soogard (2021), the prevalence of COVID-19 patients with pneumonia who received antibiotics (single/combination) was $43.8 \%$. However, the main antibiotics used for COVID-19 patients with CAP or HAP in that study were amoxicillin-clavulanate (22.2\%), piperacillin/ tazobactam (18.5\%), and ceftriaxone (8.6\%) [8]. The use of levofloxacin and azithromycin was suitable with the COVID-19 treatment protocol recommended by the Indonesian Doctor Association. The use of azithromycin or levofloxacin IV/PO for 5-7 days can be given if the bacterial infection is suspected in COVID-19 patients [10]. Patients also received steroid therapy in this study. This result is supported by Liu et al. study that $25.9 \%$ of COVID-19 patients in Wuhan were also given glucocorticoids. Antiviral was negatively associated with mortality in severe COVID-19 patients (OR: 0.17, p: 0.008). Oseltamivir reduces the risk of death in severe COVID-19 patients, while glucocorticoids increase the risk of progressivity COVID-19 from mild to severe (OR: 3.79; $\mathrm{p}<0.001$ ) [13].

This research indicates that the COVID-19 severity was statistically associated with the clinical outcome of COVID-19 confirmed and pneumonia patients ( $\mathrm{p}<0.001, \mathrm{OR}=26.714,95 \% \mathrm{CI}$ : 5.526-129.135). Confirmed COVID-19 with severe or critical diseases has a greater risk for death than non-severe patients in this study. Those results are supported by Rahmani et al. which states that the mortality rate of COVID-19 patients depends on the severity of the disease [14]. The estimated mortality rate of COVID-19 patients with severe disease was greater (32.5\%) than COVID-19 patients with the non-severe disease (1.1\%) [15].

The severe COVID-19 disease makes patients are more susceptible to severe symptoms and a higher mortality rate, especially for patients with comorbidities, including hypertension, cardiovascular disease, and diabetes [16]. Severe disease in COVID-19 patients is characterized by massive alveolar damage and progressive respiratory failure that may be associated with cytokine storm events. Cytokine storm events are characterized by an increase in pro-inflammatory cytokines such as interleukin-6 (IL-6). IL-6 is a multifunctional cytokine that is involved in the pathogenesis of acute lung injury. These cytokines are produced mainly by pulmonary AM and act as functional mediators for recruiting lymphocytes into lung lesions. The secretion of these cytokines can exacerbate lung injury and accelerate mortality [17].

In this study, comorbidity had a significant effect $(\mathrm{p}<0.05)$ according to the bivariate analysis with an odds ratio value of 4 , which means that COVID-19 patients with pneumonia who have comorbidities have 4 times greater chance of dying than patients who have no comorbidities. This result is consistent with the previous research that 
comorbidities can increase the risk of death and disease severity in COVID-19 patients [18].

The variables of age and gender did not affect the clinical outcome of the research subjects. The results of this study differ from a cohort study in China which states that age significantly affects mortality in COVID-19 patients [19]. Another study by Zheng et al. also stated that a greater proportion of patients aged $>65$ years died and had a critical illness [20]. Elderly COVID-19 patients experience decreased $\mathrm{T}$ and $\mathrm{B}$ cell function and cytokine overproduction resulting in a deficiency in controlling viral replication and prolonging the pro-inflammatory response [21]

A meta-analysis of 13 studies showed that male was a risk factor for COVID-19 disease progression [21]. Male patients were higher in a critical illness $(p<0.001)$ [20]. Biological, immunological, and endocrine differences explain the reasons for the different outcomes in the two sexes [22]. Women are at lower risk for viral infections because estrogen and progesterone can help enhance innate and adaptive immune responses. Women also have many X-chromosome-related immune genes. Therefore, women had high immune reactivity after viral infection and the viral clearance process will be accelerated [23].

The limitations of this research were the small sample size. Second, the research data collection was retrospective by patient medical records in one referral hospital for COVID-19 patients in Indonesia. Further research is needed with larger sample size or area to represent the population. Third, the effect of therapy on clinical outcomes was not analyzed in this research. Hence, the most effective therapy cannot be known for COVID-19 patients.

\section{CONCLUSION}

This research demonstrated that the risk factor for clinical outcomes of the confirmed COVID-19 with pneumonia patients was disease severity. Patients with severe illness have a greater risk to die. Patients received antiviral, antibiotics, and steroids during a treatment period. The most common antibiotics were levofloxacin IV and azithromycin per oral, while oseltamivir was the most frequently prescribed antiviral for the patients. The percentage of patients that used steroids was $41.7 \%$. Future research is needed to find the most effective treatment for COVID-19 patients.

\section{ACKNOWLEDGMENT}

The authors thank Fatmawati General Hospital Jakarta for allowing and facilitating authors in data collection.

\section{AUTHORS' CONTRIBUTIONS}

Nofria Rizki Amalia Harahap and Ahmad Subhan consulted with Retnosari Andrajati to arrange the concept of the study. Nofria Rizki Amalia Harahap collected and analyzed the data. All authors discussed the final article.

\section{CONFLICTS OF INTEREST}

All authors declared no conflict of interest related to this research, and publication of this article.

\section{AUTHOR'S FUNDING}

The authors stated that there was no source of funding for this research.

\section{REFERENCES}

1. World Health Organization. WHO Coronavirus Disease Dashboard. Geneva: World Health Organization; 2021. Available from: https:// www.who.int/emergencies/diseases/novel-coronavirus-2019.

[Last accessed on 2021 Aug 09]

2. Ministry of Health of the Republic of Indonesia. Current Situation of the Development of COVID-19 in Indonesia 9 August 2021; 2021. Available from: https://www.infeksiemerging.kemkes.go.id/dashboard/ covid-19. [Last accessed on 2021 Aug 09].

3. Li H, Liu SM, Yu XH, Tang SL, Tang CK. Coronavirus disease 2019 (COVID-19): Current status and future perspectives. Int J Antimicrob Agents 2020;55:105951.

4. Sharov KS. SARS-CoV-2-related pneumonia cases in pneumonia picture in Russia in March-May 2020: Secondary bacterial pneumonia and viral co-infections. J Glob Health 2020;10:020504

5. Mirzaei R, Goodarzi P, Asadi M, Soltani A, Aljanabi H, Jeda AS, et al. Bacterial co-infections with SARS-CoV-2. IUBMB Life 2020;72:2097-111.

6. World Health Organization. COVID-19 Clinical Management Living Guidance 25 January 2021. Geneva: World Health Organization; 2021.

7. Rozaliyani A, Ary S, Findra S, Titania N. Factors associated with death in COVID-19 patients in Jakarta, Indonesia: An epidemiological study. Acta Med Indones 2020;52:246-54

8. Søgaard KK, Baettig V, Osthoff $M$, Marsch S, Leuzinger K, Schweitzer $\mathrm{M}$, et al. Community-acquired and hospital-acquired respiratory tract infection and bloodstream infection in patients hospitalized with COVID-19 pneumonia. J Intensive Care 2021;9:10.

9. Manna S, Baindara P, Mandal SM. Molecular pathogenesis of secondary bacterial infection associated to viral infections including SARS-CoV-2. J Infect Public Health 2020;13:1397-404.

10. Indonesian Doctors Associations. Guidelines for COVID-19 in Indonesian $3^{\text {rd }}$ Edition December 2020. Jakarta: Indonesian Doctors Associations; 2020.

11. Frediansyah A, Tiwari R, Sharun K, Dhama K, Harapan H. Antivirals for COVID-19: A critical review. Clin Epidemiol Glob Health 2021;9:90-98.

12. Acosta PE, Charles F. Antiviral agents (nonretroviral). In: Brunton LL, Chabner BA, Knollmann BJ, editors. Goodman and Gilman's: The Pharmacological Basis of Therapeutics. $12^{\text {th }}$ ed. New York: McGrawHill Education; 2011. p. 1608.

13. Liu J, Zhang S, Wu Z, Shang Y, Dong X, Li G, et al. Clinical outcomes of COVID-19 in Wuhan, China: A large cohort study. Ann Intens Care 2020;10:99.

14. Rahmani H, Davoudi-Monfared E, Nourian A, Nabiee M, Sadeghi S, Khalili $\mathrm{H}$, et al. Comparing outcomes of hospitalized patients with moderate and severe COVID-19 following treatment with hydroxychloroquine plus atazanavir/ritonavir. Daru 2020;28:625-34.

15. Li X, Xu S, Yu M, Wang K, Tao Y, Zhou Y, et al. Risk factors for severity and mortality in adult COVID-19 inpatients in Wuhan. J Allergy Clin Immunol 2020;146:110-8.

16. Jin S, Hu W. Severity of COVID-19 and treatment strategy for patient with diabetes. Front Endocrinol 2021;12:602735.

17. Sun Y, Dong Y, Wang L, Xie H, Li B, Chang C, et al. Characteristics and prognostic factors of disease severity in patients with COVID-19: The Beijing experience. J Autoimmun 2020;112:102473.

18. Jutzeler CR, Bourguignon L, Weis CV, Tong B, Wong C, Rieck B, et al. Comorbidities, clinical signs and symptoms, laboratory findings, imaging features, treatment strategies, and outcomes in adult and pediatric patients with COVID-19: A systematic review and metaanalysis. Travel Med Infect Dis 2020;37:101825.

19. Zhou F, Yu T, Du R, Fan G, Liu Y, Liu Z, et al. Clinical course and risk factors for mortality of adult inpatients with COVID-19 in Wuhan, China: A retrospective cohort study. Lancet 2020;395:1054-62.

20. Zheng Z, Peng F, Xu B, Zhao J, Liu H, Peng J, et al. Risk factors of critical and mortal COVID-19 cases: A systematic literature review and meta-analysis. J Infect 2020;81:e16-25.

21. Cen Y, Chen X, Shen Y, Zhang XH, Lei Y, Xu C, et al. Risk factors for disease progression in patients with mild to moderate coronavirus disease 2019-a multi-centre observational study. Clin Microbiol Infect 2020;26:1242-7.

22. Galbadage T, Peterson BM, Awada J, Buck AS, Ramirez DA, Wilson J, et al. Systematic review and meta-analysis of sex-specific COVID-19 clinical outcomes. Front Med 2020;7:348.

23. Chen X, Wenjia H, Jiaxin L, Pingzheng M, Zhang Y, Jiang Q, $\mathrm{Ma} \mathrm{Z}$, et al. Hypertension and diabetes delay the viral clearance in COVID-19 patients. medRexiv 2020;2020:40774 